\title{
THE USE OF ENTROPY INDEX FOR GENDER INEQUALITY ANALYSIS
}

\section{U. EKHOSUEHI AND A. A. OSAGIEDE}

(Received 6, October 2009; Revision Accepted 11, January 2010)

\begin{abstract}
In the Millennium Declaration, the proportion (or ratio) of females to males in a given sector is used as the indicator for gender inequality. A critical limitation in the proportion (or ratio) statistic is that it does not include randomness in gender disparity over a period of time. It is well-known that randomness, which is a key ingredient in studying the behaviour of a system, is measured using entropy. This paper presents the use of entropy as an alternative measure for gender inequality in a sector of an economy.
\end{abstract}

KEYWORDS: Entropy; gender inequality; Millennium Declaration; randomness.

\section{INTRODUCTION}

Discrimination against women in all fields of human endeavour has resulted to a crushing problem of gender inequality. As stated in the Millennium Declaration, gender inequality is indicated in the ratios of females to males enrolled at all levels of education (primary, secondary, and tertiary levels); the ratio of literate females to males 15-24 years old; the share of females in wage employment in the non-agricultural sector; and the proportion of seats held by women in national parliament (Ogbonna, 2006). Earlier studies on inequalities in Nigerian education show that males have greater access to education than females and the gap in access between males and females tends to widen as they transit from primary to tertiary level of education (Nwagwu, 1998). Nwagwu (1998) identified enrolment ratio as a relevant index to judge the extent of female access to education in Nigeria, and also reported that data on enrolment ratios are often scanty.

The motivation for this study is based on the priority of the Millennium Declaration for gender equality as the target of achieving gender equality by 2015 is fast approaching, and on the assertion by Oroge (1999) that many legislations have been enacted which provide equal opportunities for women and men and also protect women from being discriminated against, but in practice, these may not necessarily be so. In this study therefore, we develop an entropy index as an alternative measure for gender inequality in a sector of an economy, and applied it to enrolment in primary and secondary schools in Nigeria using data in Nwagwu (1998).

\section{CONCEPTUAL FRAMEWORK}

It is a well-known result that for a probability distribution

$\Delta_{n}=\left\{\left(p_{1}, p_{2}, \ldots p_{n}\right): p_{i} \geq 0, \sum_{i=1}^{n} p_{i}=1\right\}$

associated with the discrete random variable $X$, the entropy is given by

$H(X)=E\left[k \log _{b}\left(\frac{1}{P\left(x_{i}\right)}\right)\right]=-k \sum_{i=1}^{n} P\left(x_{i}\right) \log _{b} P\left(x_{i}\right)$

where $k$ is a constant. This is a measure of the degree of randomness in the system (Vassiliou, 1984). For $k=1$, equation (1) is referred to as Shannon entropy (see Ciuperca and Girardin, 2005).

Shannon entropy has the property of symmetry i.e. the measure is unchanged if the outcomes $x_{i}$ are re-ordered e.g. $H_{n}\left(P_{1}, P_{2}, \ldots\right)=H_{n}\left(P_{2}, P_{1}, \ldots\right)$, etc. where $H_{n}(\bullet)$ is the entropy measure. Shannon entropy increases with the number of outcomes i.e.

$$
H_{n}\left(P_{1}, \ldots, P_{n}\right) \leq H_{n}\left(\frac{1}{n}, \ldots, \frac{1}{n}\right)<H_{n+1}\left(\frac{1}{n+1}, \ldots, \frac{1}{n+1}\right)
$$

V. U. Ekhosuehi, Department of Maths, University of Benin, Nigeria,

A. A. Osagiede, Department of Maths, University of Benin, Nigeria, 
The properties of Shannon entropy are stated in the publication of Departmento de Matematica (2001). Shannon entropy as used in operations research and in hypothesis selection has been critically examined by White (1975). With Shannon formula the entropy of a system can be calculated from the entropy of its sub-systems if we know how the sub-systems interact with each other. For instance, for positive integers $b_{i}$ where $b_{1}+\ldots+b_{k}=n$, we have

$H_{n}\left(\frac{1}{n}, \ldots, \frac{1}{n}\right)=H_{k}\left(\frac{b_{1}}{n}, \ldots, \frac{b_{k}}{n}\right)+\sum_{i=1}^{k} \frac{b_{i}}{n} H_{b_{i}}\left(\frac{1}{b_{i}}, \ldots, \frac{1}{b_{i}}\right)$

Shannon entropy is given by Girardin and Limnios (2003) for a finite measure $\mu^{*}$ absolutely continuous with respect to a $\sigma$-finite measure $\mu$ with Radon-Nikodym derivative $f$ as

$$
S_{\mu}(f)=-\int f(x) \log f(x) d \mu(x)
$$

For a discrete measure $\mu^{*}$ with support $E$,

$$
S\left(\mu^{*}\right)=-\sum_{i \in E} \mu_{i}^{*} \log \mu_{i}^{*}
$$

Applications of entropy abound in literature. Wilson (1970) had earlier discussed the use of entropy in system modelling. Entropy has been applied to oil spill problem (Freund and Saxena, 1984; and Thomas, 1979), cost functions (Dinkel and Kochenberger, 1979; and Paris and Howitt, 1998), hazard rate function estimation (Ebrahimi, 2000), international trade (Pulliainen, 1970), combat degradation (Rodrigues, 1989), queuing systems (Guiasu, 1986), manpower systems (McClean and Abodunde, 1978; McClean, 1986; and Omosigho and Osagiede, 1999), external debt profile (Ekhosuehi and Osagiede, 2007a; 2007b; Osagiede and Ekhosuehi, 2007), industrial and employment concentration (Horowitz, 1970), unemployment scenario (Ekhosuehi and Osagiede, 2007c) and income inequality (Mussard et al, 2003).

\section{THE MODEL}

In order to derive a measure which accounts for the degree of randomness for gender inequality in a given sector, say sector $i$, over the time interval $\left[1, T_{i}\right]$, where $T_{i}$ is the maximum period of time for which data are available for sector $i$, we need to compare the changes in population of males and females for period $t$, $\left\{t: 1 \leq t \leq T_{i}\right\}$, in sector $i$. The change in population in any sector is often due to wastages and new recruits employed to fill vacancies. Let $n_{i}^{m}(t)$ be the number of males in sector $i$, at period $t$, and let $n_{i}^{f}(t)$ be the number of females in sector $i$, at period $t$. For $1 \leq \xi \leq T_{i}-1$, define $\Delta_{i}^{f}(t)=\frac{n_{i}^{f}(t)-n_{i}^{f}(\xi)}{t-\xi}, \Delta_{i}^{m}(t)=\frac{n_{i}^{m}(t)-n_{i}^{m}(\xi)}{t-\xi}$, and $z_{i}(t)= \begin{cases}1 & \text { if } \quad \Delta_{i}^{f}(t) \geq \Delta_{i}^{m}(t) \\ 0 & \text { if } \Delta_{i}^{f}(t)<\Delta_{i}^{m}(t)\end{cases}$

The number of times for which the change in number of females is not less than the change in number of males in sector $i$ denoted as $Y_{i}$ is

$$
Y_{i}=\sum_{t=1}^{T_{i}} z_{i}(t)
$$

Let $\theta_{i}$ be the probability of having $z_{i}(t)=1$, so that the probability of having $z_{i}(t)=0$ is $1-\theta_{i}$. We assume that $Y_{i}$ is a random variable with the distribution $Y_{i} \sim$ binomial $\left(T_{i}, \theta_{i}\right)$ i.e.

$$
P\left(Y_{i}=y\right)=\left(\begin{array}{c}
T_{i} \\
y
\end{array}\right) \theta_{i}{ }^{y}\left(1-\theta_{i}\right)^{T_{i}-y}, \quad y=0,1, \ldots, T_{i} .
$$

From equation (1), we obtain

$$
H_{i}^{R}=-k \sum_{y=0}^{T_{i}}\left[\left(\begin{array}{c}
T_{i} \\
y
\end{array}\right) \theta_{i}^{y}\left(1-\theta_{i}\right)^{T_{i}-y}\left\{y \ln \left(\frac{\theta_{i}}{1-\theta_{i}}\right)+T_{i} \ln \left(1-\theta_{i}\right)+\ln \left(\begin{array}{c}
T_{i} \\
y
\end{array}\right)\right\}\right]
$$

To constrain the entropy measure to a finite range of $[0,1]$, we apply Jensen inequality (Ruszczynski and Shapiro, 2003). Thus,

$$
0 \leq-E\left\{y \ln \left(\frac{\theta_{i}}{1-\theta_{i}}\right)+T_{i} \ln \left(1-\theta_{i}\right)+\ln \left(\begin{array}{c}
T_{i} \\
y
\end{array}\right)\right\} \leq-\ln E\left[\left(\begin{array}{c}
T_{i} \\
y
\end{array}\right) \theta_{i}{ }^{y}\left(1-\theta_{i}\right)^{T_{i}-y}\right]=\ln \left(T_{i}+1\right)
$$


It follows that

$0 \leq-2 E\left\{y \ln \left(\frac{\theta_{i}}{1-\theta_{i}}\right)+T_{i} \ln \left(1-\theta_{i}\right)+\ln \left(\begin{array}{c}T_{i} \\ y\end{array}\right)\right\} \sum_{t=1}^{T_{i}} n_{i}^{f}(t) \leq \ln \left(T_{i}+1\right) \sum_{t=1}^{T_{i}}\left(n_{i}^{m}(t)+n_{i}^{f}(t)\right)$ holds.

Taking $k=\frac{2 \sum_{t=1}^{T_{i}} n_{i}^{f}(t)}{\ln \left(T_{i}+1\right) \sum_{t=1}^{T_{i}}\left(n_{i}^{m}(t)+n_{i}^{f}(t)\right)}$, we obtain

$H_{i}^{R^{*}}=-\frac{2 \sum_{t=1}^{T_{i}} n_{i}^{f}(t)}{\ln \left(T_{i}+1\right) \sum_{t=1}^{T_{i}}\left(n_{i}^{m}(t)+n_{i}^{f}(t)\right)} \sum_{y=0}^{T_{i}}\left[\left(\begin{array}{c}T_{i} \\ y\end{array}\right) \theta_{i}^{y}\left(1-\theta_{i}\right)^{T_{i}-y}\left\{y \ln \left(\frac{\theta_{i}}{1-\theta_{i}}\right)+T_{i} \ln \left(1-\theta_{i}\right)+\ln \left(\begin{array}{c}T_{i} \\ y\end{array}\right)\right\}\right]$

(9)

and $0 \leq H_{i}^{R^{*}} \leq 1 . H_{i}^{R^{*}}$ is the entropy index for gender inequality in sector $i$. $H_{i}^{R^{*}}=0$ when $P\left(Y_{i}=0\right)=1$, and $P\left(Y_{i}=1\right)=P\left(Y_{i}=2\right)=\ldots=P\left(Y_{i}=T_{i}\right)=0$ and represents the situation of no randomness and a very strong dominance of males in sector $i . H_{i}^{R^{*}}=1$ is achieved when $P\left(Y_{i}=0\right)=P\left(Y_{i}=1\right)=\ldots=P\left(Y_{i}=T_{i}\right)=\frac{1}{T_{i}+1} \quad$ and the total number of females equals the total number of males in the period under consideration; it represents perfect randomness and gender equality in sector $i$. For intermediate values, the entropy index summarizes in one figure the degree of randomness and gender inequality in the sector. If there are $s$ sectors in the economy, we define the average entropy index as

$H^{R^{*}}=\frac{1}{s} \sum_{i=1}^{s} H_{i}^{R^{*}}$

\section{APPLICATION}

In this section, we illustrate the use of the entropy index to measure gender inequality in primary and secondary schools in Nigeria. There has been an impressive increase in enrolments in primary and secondary schools in Nigeria over the years. In spite of the tremendous growth at these levels, the female gender may not have had equal opportunity to education as their male counterparts. Since data on enrolments for males and females are usually given (or sometimes computed from information provided) the entropy index developed in section 3 can be applied to school enrolment. More so, the entropy index comprises pooled proportion of females in the sector and degree of randomness of the change in population of both genders over the years. We now illustrate the use of the entropy index using enrolment data as presented in Tables I and II.

Table I: Enrolments in primary schools

\begin{tabular}{|c|c|c|}
\hline \multirow{2}{*}{ Year } & \multicolumn{2}{|c|}{ Enrolments } \\
\cline { 2 - 3 } & Total & Female $\%$ \\
\hline 1912 & 21,153 & 14.9 \\
\hline $1975 / 76$ & $6,165,547$ & 42.6 \\
\hline $1983 / 84$ & $14,677,483$ & 43.7 \\
\hline $1985 / 86$ & $12,914,870$ & 45.6 \\
\hline $1990 / 91$ & $13,607,318$ & 43.2 \\
\hline $1993 / 94$ & $15,870,280$ & 43.7 \\
\hline
\end{tabular}

Table II: Enrolments in secondary schools

\begin{tabular}{|c|c|c|}
\hline \multirow{2}{*}{ Year } & \multicolumn{2}{|c|}{ Enrolments } \\
\cline { 2 - 3 } & Total & Female $\%$ \\
\hline $1975 / 76$ & 745,717 & 7.2 \\
\hline $1980 / 81$ & $1,995,417$ & 33.8 \\
\hline $1985 / 86$ & $3,088,711$ & 43.1 \\
\hline $1990 / 91$ & $2,893,918$ & 42.8 \\
\hline $1993 / 94$ & $4,032,083$ & 45.9 \\
\hline
\end{tabular}

Source: Extracted from Nwagwu (1998).

The enrolments for each gender are computed from the tables using: 
$n_{i}^{f}(t)=\beta_{i}^{f}(t)\left(n_{i}^{m}(t)+n_{i}^{f}(t)\right)$ and $n_{i}^{m}(t)=\left[1-\beta_{i}^{f}(t)\right]\left(n_{i}^{m}(t)+n_{i}^{f}(t)\right)$, where $\beta_{i}^{f}(t)$ is the percentage of female enrolment in level $i$, at period $t$. For instance, we obtain results for 1975/76 and 1983/84 in primary school as follows. For 1975/76, we use the code $t=2$, $n_{1}^{f}(2)=42.6 \% \times 6,165,547 \approx 2,626,523, \quad n_{1}^{m}(2)=(1-42.6 \%) \times 6,165,547 \approx 3,539,024$, and for 1983/84, $t=3$, $n_{1}^{f}(3)=43.7 \% \times 14,677,483 \approx 6,414,060, \quad n_{1}^{m}(3)=(1-43.7 \%) \times 14,677,483 \approx 8,263,423$.

$\Delta_{1}^{f}(3)=\frac{6,414,060-2,626,523}{3-2}=3,787,537, \quad \Delta_{1}^{m}(3)=\frac{8,263,423-3,539,024}{3-2}=4,724,399 . \quad$ Since $\Delta_{1}^{m}(3)>\Delta_{1}^{f}(3), z_{1}(3)=0$. Similarly, other results are obtained. $\theta_{i}$ is computed using the maximum likelihood value: $\hat{\theta_{i}} \quad \sum_{t=1}^{T_{i}} z_{i}(t)$ $\hat{\theta}_{i}=\frac{\sum_{t=1} z_{i}(t)}{T_{i}}$. For primary school, we have $\hat{\theta}_{1}=\frac{1}{5}$ as $T_{1}=5$. Using the formula in equation (9), we obtain the entropy index for primary and secondary schools respectively for each time interval as $H_{1}^{R^{*}}=0.6086$ and $H_{2}^{R^{*}}=0.6127$. As earlier mentioned, the entropy index for intermediate values summarizes in one figure the degree of randomness and gender inequality in the sector. Since $0<H_{1}^{R^{*}}<H_{2}^{R^{*}}<1$, the entropy indices imply that gender inequality (against females) in the periods under review are not severe, and that greater educational opportunities abound at the secondary level.

Using the enrolment stock in Tables I and II, Nwagwu (1998) analysed gender inequality in both primary and secondary schools using enrolment ratio statistics as presented in Tables III and IV.

Table III: Enrolment ratios in primary schools

\begin{tabular}{|l|l|l|l|l|}
\hline \multirow{2}{*}{ Year } & Enrolments & \multicolumn{3}{l|}{ Enrolment ratio (\%) } \\
\cline { 2 - 5 } & Total & Female \% & Males & Females \\
\hline 1912 & 21,153 & 14.9 & NA & NA \\
\hline $1975 / 76$ & $6,165,547$ & 42.6 & NA & NA \\
\hline $1983 / 84$ & $14,677,483$ & 43.7 & 105 & 81 \\
\hline $1985 / 86$ & $12,914,870$ & 45.6 & 85 & 69 \\
\hline $1990 / 91$ & & & & \\
\hline $1993 / 94$ & $13,607,318$ & 43.2 & 75 & 60 \\
\hline
\end{tabular}

Table IV: Enrolment ratios in secondary schools

\begin{tabular}{|l|l|l|l|l|}
\hline \multirow{2}{*}{ Year } & Enrolments & \multicolumn{3}{l|}{ Enrolment ratio (\%) } \\
\cline { 2 - 5 } & Total & Female \% & Males & Females \\
\hline $1975 / 76$ & 745,717 & 7.2 & NA & NA \\
\hline $1980 / 81$ & $1,995,417$ & 33.8 & 27 & 14 \\
\hline $1985 / 86$ & $3,088,711$ & 43.1 & NA & NA \\
\hline $1990 / 91$ & $2,893,918$ & 42.8 & 30 & 25 \\
\hline $1993 / 94$ & $4,032,083$ & 45.9 & 32 & 27 \\
\hline
\end{tabular}

Note: NA means not available

Source: see Nwagwu (1998).

The results (enrolment ratios) in Tables III and IV show some ambiguity. For instance, how do an individual interpret enrolment ratio for males of $105 \%$ and that for females of $81 \%$ in the $1983 / 84$ session in Table III? From the acronym NA in Tables III and IV, it can be inferred that data on enrolment ratios are scanty; as earlier reported by Nwagwu (1998). This is also a limitation to the use of enrolment ratios for gender inequality in the Nigerian education sector. Furthermore, inferences from enrolment ratios as mentioned in Nwagwu (1998) do not state the degree of randomness of gender disparity. For this reason, the entropy index developed in section 3 is a better measure than enrolment ratio statistics.

\section{CONCLUSION}

In this study, the fundamental statistical entropy measure has been modified and used as an alternative measure for gender inequality. The entropy index developed in this study is mathematically tractable and it encapsulates pooled proportion of females in the sector and degree of randomness of the change in population of both genders over the years. It application to primary and secondary enrolments in Nigeria shows that gender inequality is not severe at these levels and that greater educational opportunities are found at the secondary level than at the primary level. More efforts are however required to eliminate the inequality gap at all levels of education by the year 2015, and preferably at all sectors of the economy in general. 


\section{REFERENCES}

Ciuperca, G. and Girardin, V., 2005. On the estimation of the entropy rate of finite Markov chains. Retrieved 24/05/2009 from http://conferences.telecom-bretagne.eu/asmda2005/IMG/pdf/proceedings/1109.pdf

Departmento de Matematica, 2001. Measures of uncertainty: Shannon's entropy. Retrieved 22/05/2009 from www.mtm.ufsc. br/ taneja/book/node3.html.

Dinkel, J. J. and Kochenberger, G. A., 1979. Constrained entropy models; solvability and sensitivity. Management Science, 25, (6): 555-564.

Ebrahimi, N., 2000. The maximum entropy method for lifetime distributions. Sankhya: The Indian Journal of Statistics, 62 A, Pt. 2: 236-243

Ekhosuehi, V. U. and Osagiede, A. A., 2007a. Proposal of entropy measure of stability of external debt stock in Nigeria. International Journal of Natural and Applied Sciences, 3, (1):85-89.

Ekhosuehi, V. U. and Osagiede, A. A., 2007b. On the measure of entropy value of external debt structure for an economy. Global Journal of Mathematical Sciences, 6, (1):57-62. Ekhosuehi, V. U. and Osagiede, A. A., 2007c. An analytic study of unemployment scenario in Nigeria. Journal of Social and Management Sciences, 12: 84-91.

Freund, D. and Saxena, U., 1984. An algorithm for a class of discrete maximum entropy problems. Operations Research, 32, (1): 210-215.

Girardin, V. and Limnios, N., 2003. On the entropy for semi-Markov processes. J. Appl. Prob. 40: 1060-1068.

Guiasu, S., 1986. Maximum entropy condition in queuing theory. J. Opl. Res. Soc., 37, (3):293-301.

Horowitz, I., 1970. Employment concentration in the common market: An entropy approach. Journal of the Royal Statistical Society, 133, (3): 463-479.

McClean, S., 1986. Extending the entropy stability measure for manpower planning. J. Opl. Res. Soc., 37, (12): 11331138.

McClean, S. and Abodunde, T., 1978. Entropy as a measure of stability in manpower system. J. Opl. Res. Soc., 29, (9):885-889.

Mussard, S., Francoise S., and Terraza, M., 2003. Decomposition of Gini and the generalised entropy inequality measures. Economics Bulletin, 4, (7): pp. 1-6. Retrieved 24/05/2009 from http://www.economicsbulletin.com/2003/volume4/EB-03D30001A.pdf

Nwagwu, C. C., 1998. Inequalities in Nigerian education: The case of women participation. In: S. O. Oriaifo and R. O. Olubor (Eds), Advances in the Field of Education: The Nigerian Experience. Institute of Education, University of Benin, Benin City, Nigeria. 124-133pp.

Ogbonna, H., 2006. (Editor). Find the money: A guide to monitoring allocations to the Millennium Development Goals through the Debt Relief Gains. ActionAid International Nigeria.

Omosigho, S. E. and Osagiede, A. A., 1999. On estimation of entropy value for an organisation. Journal of the Nigerian Association of Mathematical Physics, 3:36-42.

Oroge, S. A., 1999. Integrating women's issues into population education program in Nigeria. In: S. O. Oriaifo and C. C. Nwagwu (Eds), Population Education in Nigeria: Themes and Perspectives. Institute of Education, University of Benin, Benin City, Nigeria. 145-154pp.

Osagiede, A. A. and Ekhosuehi, V. U., 2007. Extending entropy stability measure to external debt structure. Journal of Science and Technology, 27, (3):156-162.

Paris, Q. and Howitt, R. E., 1998. An analysis of ill-posed production problems using maximum entropy. Amer. J. Agr. Econ, 80: 124-138.

Pulliainen, K., 1970. Entropy-measures for international trade. The Swedish Journal of Economics, 72, (1): 40-53. 
Rodrigues, F. C., 1989. A proposed entropy measure for assessing combat degradation. J. Opl. Res. Soc., 40, (8):789-793.

Ruszczynski, A. and Shapiro, A., 2003. Stochastic programming models. In: A. Ruszczynski and A. Shapiro (Eds), Handbooks in Operations Research and Management Science: Stochastic Programming. Elsevier, Amsterdam. 1-64pp.

Thomas, M. U., 1979. A generalised maximum entropy principle. Operations Research, 27, (6): 1188-1196.

Vassiliou, P. -C. G., 1984. Entropy as a measure of the experience distribution in a manpower system. J. Opl. Res. Soc., 35, (11): 1021-1025.

White, D. J., 1975. Entropy and decision. Opl. Res. Q., 26, (I): 15-23.

Wilson, A. G., 1970. The use of the concept of entropy in system modelling. Opl. Res. Q., 21: 247-265. 